\title{
Total Usual Intake of Shortfall Nutrients Varies With Poverty Among US Adults
}

\author{
Regan L. Bailey, PhD, MPH, RD ${ }^{1}$; Sharon R. Akabas, $\mathrm{PhD}^{2}$; Erin E. Paxson, $\mathrm{MS}^{2}$; \\ Sowmyanarayanan V. Thuppal, MD, $\mathrm{PhD}^{1}$; Shilpa Saklani, $\mathrm{MS}^{3}$; Katherine L. Tucker, $\mathrm{PhD}^{3}$
}

\begin{abstract}
Objective: To examine shortfall nutrient intakes (ie, calcium, folate, potassium, magnesium, and vitamins A, C, D, and E) by poverty-to-income ratio (PIR).

Design: National Health and Nutrition Examination Survey 2011-2012, a nationally representative, cross-sectional survey.

Participants: US adults with complete data on poverty status and diet were included $(\mathrm{n}=4,524)$.

Analysis: The National Cancer Institute method was used to estimate total usual micronutrient intakes from foods, beverages, medications, and dietary supplements reported on 2 24-hour dietary recalls using measurement error correction.

Main Outcome Measures: Calcium, folate, potassium, magnesium, and vitamins A, C, D, and E across 3 PIR categories: $<130 \%, 130 \%$ to $350 \%$, and $\geq 350 \%$.

Results: Mean intakes of folate, vitamin C, and vitamin D were significantly greater in men, and magnesium in women, across all PIR categories. Except for calcium in men and vitamin C in women, the highest PIR category had significantly higher mean total usual intakes of all remaining shortfall micronutrients. Importantly, men and women in the highest PIR category $(\geq 350 \%)$ were significantly less likely to have intakes below the Estimated Average Requirement across all micronutrients compared with those in the lower PIR categories.

Conclusions and Implications: Even with dietary supplements, large proportions of US adults have micronutrient intakes below the Estimated Average Requirement. Adults at the highest adjusted income have higher micronutrient intakes and lower risk of inadequacy than those with lower incomes.

Key Words: micronutrients, vitamins, minerals, diet quality, NHANES, dietary supplements, poverty, shortfall nutrients (J Nutr Educ Behav. 2017;49:639-646.)
\end{abstract}

Accepted November 15, 2016. Published online May 20, 2017.

\section{INTRODUCTION}

The National Health and Nutrition Examination Survey (NHANES) monitored indicators of nutrition and health for the past 50 years, and trends have been identified using the multitude of sequential, cross-sectional reports. First, the quantity and variety of food available to Americans has increased over time, leading to considerable changes in dietary intakes. ${ }^{1}$ Second, total energy consumption, portion size, and foods consumed away from the home have increased over time. ${ }^{2-4}$ Third, a substantial proportion of the US population does not meet federal nutrition standards for most nutrientdense food groups although it overconsumes energy-dense and empty

\footnotetext{
${ }^{1}$ Department of Nutrition Science, Purdue University, West Lafayette, IN

${ }^{2}$ Institute of Human Nutrition, Columbia University, New York, NY

${ }^{3}$ Department of Clinical Laboratory and Nutritional Sciences, University of MassachusettsLowell, Lowell, MA

Conflict of Interest Disclosure: The authors' conflict of interest disclosures can be found online with this article on www.jneb.org.

Address for correspondence: Regan L. Bailey, PhD, MPH, RD, Department of Nutrition Science, Purdue University, 700 West State St, West Lafayette, IN 47906; Phone: (765) 4942829; E-mail: regan.bailey@gmail.com

(C)2016 The Authors. Published by Elsevier, Inc. on behalf of the Society for Nutrition Education and Behavior. This is an open access article under the CC BY-NC-ND license (http://creativecommons.org/licenses/by-nc-nd/4.0/).

http://dx.doi.org/10.1016/j.jneb.2016.11.008
}

calories. ${ }^{5,6}$ Fourth, dietary supplement use has increased over time. ${ }^{7}$ Finally, prevalence of food-related poverty and food insecurity has increased. ${ }^{8}$ Although no causal inferences can be drawn from cross-sectional monitoring data, these food and economic trends have occurred concurrently with higher rates of obesity and deserve careful evaluation..$^{9-12}$

It is well established that nutrient-rich foods tend to be more expensive than lower-quality foods. ${ }^{13-15}$ Although the cost of food in the US is less than that in other similarly developed countries, ${ }^{16}$ people with lower incomes are more likely to have lower nutrient-dense diets ${ }^{17}$ and to devote a larger proportion of thefamilyincometowardfoodpurchases than are individuals with higher incomes. ${ }^{18}$ The proportion of Americans living in poverty in the US increased from $12.2 \%$ in 2000 to $14.8 \%$ in 2014. ${ }^{19,20}$ Dietary supplement use has been shown to be highest among the most affluent population ${ }^{21,22}$; 
paradoxically, adult supplement users have better micronutrient intakes from the diet. ${ }^{23,24}$ However, little is known about how poverty affects diet quality in terms of micronutrient intakes with the inclusion of dietary supplements at the national level. Therefore, the purpose of this study was to examine micronutrient intakes by poverty-toincome ratio (PIR) among US adults, using data from the most recent 20112012 NHANES.

\section{METHODS}

\section{Study Design, Participants, and} Setting

Collected by the Centers for Disease Control and Prevention, National Center for Health Statistics, NHANES is a cross-sectional survey using a stratified, multistage probability design to obtain a nationally representative sample of the civilian, noninstitutionalized US population. $^{25}$ Data from the 20112012 NHANES were used for these analyses. The analytic sample included nonpregnant, adult participants (aged $\geq 19$ years) who had complete PIR $(\mathrm{n}=4,524)$ and 24-hour dietary intake data. Written, informed consent was obtained for all participants or proxies. Review by the institutional review board was not required for this study because the survey protocol was approved by the Research Ethics Review Board at the National Center for Health Statistics and the data are public access.

The NHANES protocol includes an in-home interview, a health examination in a mobile examination center, and a follow-up telephone call about 3-10 days after the examination. Demographic data, including age, gender, education, and race/ethnicity, were collected via computer-assisted software in the home interview. The PIR is a measure that represents the ratio of household income to the poverty threshold after adjusting for geographic location and family size, developed by the Department of Health and Human Services. Three PIR categories were constructed: $<130 \%, 130 \%$ to $350 \%$, and $\geq 350 \%$. A PIR $<130 \%$ is the income eligibility criterion for participation in the Supplemental Nutrition Assistance Program (SNAP) (the former Food Stamps Program), and these cutoff points were previously used in NHANES analyses because they were shown to differentiate among health, dietary supplement use, and nutrition indicators. $10,21,26,27$

Dietary data in NHANES came from the US Department of Agriculture, ${ }^{28}$ Agricultural Research Service, What We Eat in America survey and were collected using the automated multiple-pass method. ${ }^{29,30}$ Two 24hour dietary recalls were collected, including the use of dietary supplements. The first recall was collected in person at the household interview; the second recall was collected via telephone. Both week and weekend days were obtained to ensure representativeness. The US Department of Agriculture, Food and Nutrient Database for Dietary Studies was used to convert foods and beverages, as reported, to their respective nutrient values. ${ }^{31}$ The researchers examined selected shortfall micronutrients for adults identified by the Dietary Guidelines for Americans: calcium (milligrams), folate (dietary folate equivalents), magnesium (milligrams), potassium (milligrams), vitamin A (retinol activity equivalents), vitamin $\mathrm{C}$ (milligrams), vitamin D (micrograms), and vitamin $\mathrm{E}$ ( $\alpha$-tocopherol equivalents).

A dietary supplement questionnaire was administered during the household interview, including showing containers to the trained interviewers to enhance accuracy. ${ }^{25}$ The time frame for the questionnaire was over the previous 30 days. For each dietary supplement the respondent reported, she or he was asked to report the consumption frequency, the dose, and the duration of use. The National Center for Health Statistics provided the average daily intake of nutrients from all dietary supplements and medications that may contain nutrients (eg, antacids) as calculated for individuals using the number of days supplement use was reported, the reported amount taken per day, and the serving size unit from the product label. Vitamins A and E from dietary supplements were not available in this survey cycle. Potassium is rarely an ingredient in dietary supplements; if it present, it is found only in very small amounts $(<15 \mathrm{mg}){ }^{32,33}$

\section{Data Analysis}

All data analyses were performed using SAS software (version 9.4; SAS Institute,
Inc, Cary, NC, 2016). Sample weights were used to account for differential nonresponse and/or no coverage and to adjust for planned oversampling of some groups. Prevalence of dietary supplement use was estimated overall and by sex using proc surveymeans. Estimates of usual intake for each micronutrient were determined using the National Cancer Institute (NCI) method $^{34,35}$ macros that produce means and percentiles of intake and probabilities of meeting the Estimated Average Requirement (EAR) for all adults with data from the 24-hour recalls $(n=4,524)$. The macros used in this analysis were specifically developed to address how dietary supplement use affects usual intake estimates incorporating information about dietary supplements from both the 24-hour and 30-day frequency questionnaires; these macros were previously used to estimate total nutrient intakes. ${ }^{36,37}$ The probability approach was used to estimate compliance with the EAR for all nutrients with an established value (ie, all shortfall nutrients except potassium). Covariates in the usual intake models included PIR (dummy coded), day of the week of dietary recall (weekend/weekday), interview sequence of the dietary recall, and dietary supplement use. To estimate total usual nutrient intake, nutrient intakes from dietary supplements were added to the adjusted usual nutrient intake from foods, as recommended. ${ }^{38}$ Percent contributions of dietary supplements to total intakes were calculated by sex and PIR. Users and nonusers of dietary supplements were also examined independently. The researchers used multiple $t$ tests to compare mean intakes and EAR compliance within sex by PIR group, with a Bonferronicorrected significant $P$ set at $\leq .005$.

\section{RESULTS}

The PIR category was classified as $<130 \%$ (A = lowest), $130 \%$ to $350 \%$ ( $\mathrm{B}=$ middle), and $\geq 350 \%(\mathrm{C}=$ highest $)$. The prevalence of dietary supplement use increased significantly in a stepwise fashion with PIR category for all adults and for both men and women (Table 1). Women had higher reported use of a dietary supplement than did men across all PIR categories.

Total usual mean intakes of several micronutrients varied by PIR category 
Table 1. Sample Size and Prevalence (\% [SE]) of Dietary Supplement Use ${ }^{a}$ by Poverty Income Ratio (PIR) Group of Adults (Aged $\geq 19$ Y), by Sex, in US, 2011-2012

\begin{tabular}{lllccccc}
\multicolumn{2}{c}{ PIR Group (\% [SE]) } & A ( $<\mathbf{1 3 0} \%)$ & B (130\% to 350\%) & C ( $\geq \mathbf{3 5 0} \%)$ & A Vs B & A Vs C & B Vs C \\
All adults, N & $52(1)$ & $38(2)$ & $49(1)$ & $63(2)$ & $<.001$ & $<.001$ & $<.001$ \\
\multirow{2}{*}{ Men, $\mathrm{n}$} & 4,524 & 1,635 & 1,545 & 1,344 & & & \\
\multirow{2}{*}{ Women, $\mathrm{n}$} & $46(2)$ & $31(2)$ & $41(2)$ & $57(3)$ & $<.001$ & $<.001$ & $<.001$ \\
& 2,273 & 781 & 788 & 704 & & & \\
$\mathrm{P}$ & $58(2)$ & $38(1.9)$ & $49(1.1)$ & $63(1.9)$ & $<.001$ & $<.001$ & $<.001$ \\
\hline
\end{tabular}

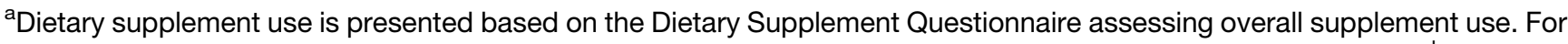
micronutrient intake estimates a user is considered if the specific micronutrient is consumed in dietary supplements; ${ }^{b}$ Statistical significance between PIR categories was assessed with multiple $t$ tests with Bonferroni-corrected significant $P$ set at $\leq .005$. Notes: The analytic sample includes all individuals aged $\geq 19$ years who were not pregnant, and who had complete information for PIR and 24-hour dietary recall data.

between men and women (Table 2). Among men, total usual mean intakes of folate, vitamin $C$, and vitamin D differed across all 3 PIR groups; calcium intake was lower in the middle than either the highest or the lowest PIR groups. For all other shortfall micronutrients (ie, magnesium, potassium, vitamin A, and vitamin E), among men, those in the highest PIR group had signifi- cantly higher intakes than either the middle or the lowest categories, which did not differ. With the exception of calcium and vitamin $\mathrm{D}$, the same trend was observed in the prevalence of risk of dietary inadequacy for all micronutrients, with significantly lower proportions with inadequate intakes among those in the highest PIR group vs the lower 2 (Table 3). Among women, total mean usual intake of magnesium differed significantly across PIR categories in the expected direction (Table 2). Mean intakes of most micronutrients (ie, calcium, folate, potassium, vitamin A, vitamin $\mathrm{D}$, vitamin $\mathrm{E}$ ) were significantly higher in the highest PIR compared with either the lowest or middle PIR groups. Risk of inadequate intake of folate and vitamin D differed significantly

Table 2. Mean (SE) Total Usual Micronutrient Intakes, by Poverty Income Ratio (PIR) Category Among Adults ( $\geq 19$ y) in US, 20112012

\begin{tabular}{|c|c|c|c|c|c|c|}
\hline Micronutrient Intake by Sex & $A(<130 \%)$ & B (130\% to $350 \%)$ & $C(\geq 350 \%)$ & A Vs B & A Vs C & B Vs C \\
\hline Men, $\mathrm{n}$ & 781 & 788 & 704 & & & \\
\hline Calcium, mg & $1,246(70)$ & $1,153(45)$ & $1,298(34)$ & .08 & .39 & $<.001$ \\
\hline Folate, DFE & 705 (30) & $800(31)$ & $931(29)$ & $<.001$ & $<.001$ & $<.001$ \\
\hline Magnesium, mg & $355(10)$ & $354(11)$ & $432(14)$ & .82 & $<.001$ & $<.001$ \\
\hline Potassium, mg & $3,136(107)$ & $3,006(85)$ & $3,537(85)$ & .06 & $<.001$ & $<.001$ \\
\hline Vitamin A, $\mu \mathrm{g}, \mathrm{RAE}^{\mathrm{a}}$ & $621(41)$ & $638(35)$ & $883(70)$ & .42 & $<.001$ & $<.001$ \\
\hline Vitamin C, mg & $126(6)$ & $147(15)$ & 227 (19) & $<.001$ & $<.001$ & $<.001$ \\
\hline Vitamin $\mathrm{D}, \mu \mathrm{g}$ & $8.3(0.7)$ & $11.5(0.8)$ & $17.1(2)$ & $<.001$ & $<.001$ & .003 \\
\hline Vitamin E, mg, ATE & $10.1(0.5)$ & $9.5(0.5)$ & $11.5(0.4)$ & .02 & $<.001$ & $<.001$ \\
\hline Women, $\mathrm{n}$ & 854 & 757 & 640 & & & \\
\hline Calcium, mg & $997(36)$ & $1,011(35)$ & $1,203(51)$ & .09 & $<.001$ & $<.001$ \\
\hline Folate, DFE & $650(21)$ & $651(17)$ & $843(20)$ & .93 & $<.001$ & $<.001$ \\
\hline Magnesium, mg & $271(7)$ & $286(8)$ & $347(12)$ & .001 & $<.001$ & $<.001$ \\
\hline Potassium, mg & $2,301(56)$ & $2,247(52)$ & $2,640(75)$ & .02 & $<.001$ & $<.001$ \\
\hline Vitamin A, $\mu \mathrm{g}, \mathrm{RAE}^{\mathrm{a}}$ & $537(25)$ & $553(29)$ & $706(32)$ & .27 & $<.001$ & $<.001$ \\
\hline Vitamin C, mg & $115(8)$ & $176(17)$ & $186(23)$ & $<.001$ & .005 & .51 \\
\hline Vitamin D, $\mu \mathrm{g}$ & $11.7(1.8)$ & $15.2(1.2)$ & $22.9(3)$ & .009 & $<.001$ & .001 \\
\hline Vitamin E, mg. ATE & $7.2(0.2)$ & $6.8(.02)$ & $9.3(0.3)$ & .06 & $<.001$ & $<.001$ \\
\hline
\end{tabular}

DFE indicates dietary folate equivalents; RAE, retinol activity equivalents; ATE, $\alpha$-tocopherol equivalents.

${ }^{a}$ Statistical significance between PIR categories was assessed with multiple $t$ tests with Bonferroni-corrected significant $P$ set at $\leq .005$.

Notes: The analytic sample includes all individuals aged $\geq 19$ years who were not pregnant, and who had with complete information for PIR and 24-hour dietary recall data. Estimates for vitamins $A$ and $E$ and potassium are based on food sources alone. 
Table 3. Prevalence (\% [SE]) of Total Usual Micronutrient Intakes Less Than Estimated Average Requirement (EAR), by Poverty Income Ratio (PIR) Groups, Among Adults in US, 2011-2012

Micronutrient Intake by Sex

Men, $\mathrm{n}$

Calcium, mg

Folate, DFE

Magnesium, mg

Vitamin A, mg, RAE

Vitamin $\mathrm{C}, \mathrm{mg}$

Vitamin $\mathrm{D}, \mu \mathrm{g}$

Vitamin E, mg, ATE $^{a}$

Women, $\mathrm{n}$

Calcium, mg

Folate, DFE

Magnesium, mg

Vitamin A, mg, RAE

Vitamin $\mathrm{C}, \mathrm{mg}$

Vitamin $\mathrm{D}, \mu \mathrm{g}$

Vitamin E, mg, ATE $^{a}$

A $<\mathbf{1 3 0} \%)$
781
$17(3)$
$5(1)$
$50(4)$
$58(6)$
$43(5)$
$79(3)$
$75(5)$
854
$44(3)$
$12(5)$
$51(4)$
$49(4)$
$41(5)$
$75(2)$
$94(2)$

PIR Group, \% (SE) < EAR

$\boldsymbol{P}$

B (130\% to $\mathbf{3 5 0} \%)$
788
$27(4)$
$6(2)$
$53(4)$
$55(6)$
$44(2)$
$69(2)$
$78(4)$
757
$48(4)$
$21(2)$
$49(3)$
$48(4)$
$37(3)$
$62(2)$
$97(1)$

$\begin{array}{ccc}\text { A Vs B } & \text { A Vs C } & \text { B Vs C } \\ & & \\ <.001 & .03 & <.001 \\ .38 & <.001 & <.001 \\ .23 & <.001 & <.001 \\ .23 & <.001 & <.001 \\ .68 & <.001 & <.001 \\ <.001 & <.001 & <.001 \\ .33 & <.001 & <.001 \\ & & \\ .11 & <.001 & <.001 \\ <.001 & <.001 & <.001 \\ .42 & <.001 & <.001 \\ .68 & <.001 & <.001 \\ .10 & <.001 & <.001 \\ <.001 & <.001 & <.001 \\ .10 & 0.01 & 0.004\end{array}$

DFE indicates dietary folate equivalents; RAE, retinol activity equivalents; ATE, $\alpha$-tocopherol equivalents.

${ }^{a}$ Estimates for vitamins $A$ and $E$ are based on food sources alone. Potassium does not have an EAR.

Notes: Statistical significance between the PIR categories was assessed with multiple $t$ tests with Bonferroni-corrected significant $P$ set at $\leq .005$. The analytic sample includes all individuals aged $\geq 19$ years and who were not pregnant, with complete information for PIR, and who had 24-hour dietary recall data.

across PIR groups for women (Table 3). For most micronutrients (ie, calcium, magnesium, vitamin $\mathrm{A}$, vitamin $\mathrm{C}$, vitamin D) the highest PIR category of women had a lower prevalence of inadequate intake compared with the middle or lowest group.

Women had higher percentages of intake from supplements compared with men for all micronutrients at all PIR levels (Figure). Across all adults, $<25 \%$ of calcium or magnesium intake came from supplements regardless of sex or PIR. In contrast, large proportions of total intake of vitamins $\mathrm{C}$ and $\mathrm{D}$ came from supplements relative to diet. Given that prevalence of use of supplements differed by each PIR category, it is not surprising that the percentage of nutrients contributed by supplements was greater across PIR categories. More than half of the vitamin D intake in US adults was from dietary supplements across all sex-PIR groups, except men, $<130 \%$.

Compared with supplement users, the prevalence of total intakes less than the EAR was substantially higher among adults not using dietary supplements, particularly for women (Supplemental Materials 1 and 2). Among both supplement users and non-supplement users (dietary intake only), total intakes for most nutrients tended to be highest among those in the highest PIR category relative to the 2 lower categories. Among non-supplement users, the proportions of men with intakes of calcium or magnesium below the EAR were lowest in the middle PIR category relative to the lowest or highest income groups.

Although the proportions with low intake were substantially lower among supplement users than the total sample, the patterns of relative intakes across PIR categories remained, with those in the highest PIR group showing higher total mean intakes and lower proportions with inadequate intakes than those in lower income groups. Exceptions, for women only, included folate, with highest mean intake in the lowest income group; vitamin D, which did not differ across PIR groups; and magnesium, in which the middle income group was most likely to have intake less than the EAR.

Importantly, the prevalence of intakes below the EAR for these shortfall nutrients was high among non-supplement users, ranging from $91 \%$ to $99 \%$ for vitamin D, $40 \%$ to $61 \%$ for magnesium, $32 \%$ to $57 \%$ for vitamin
C, $18 \%$ to $68 \%$ for calcium, and to $2 \%$ to $31 \%$ for folate, across sex and PIR groups. Even among supplement users, shortfalls persisted. Proportions not meeting the EAR among those using supplements ranged from 9\% to $33 \%$ for magnesium, $13 \%$ to $24 \%$ for vitamin $\mathrm{D}, 5 \%$ to $23 \%$ for calcium, $3 \%$ to $10 \%$ for vitamin C, and to $0 \%$ to $8 \%$ for folate (Supplemental Materials 1 and 2).

\section{DISCUSSION}

This study adds key information about how the use of dietary supplements contributes substantially to the diets of adults who use these products, and suggests that micronutrient intakes vary considerably by poverty status among US adults. A major finding of this work was that those at the highest PIR category had nutrient intakes that were higher than those in the lowest PIR category but were also higher than those in the middle PIR category. These findings point to major limitations in dietary quality among large proportions of the US adults, which suggest that food choices contribute to nutrient inadequacy in the population beyond 


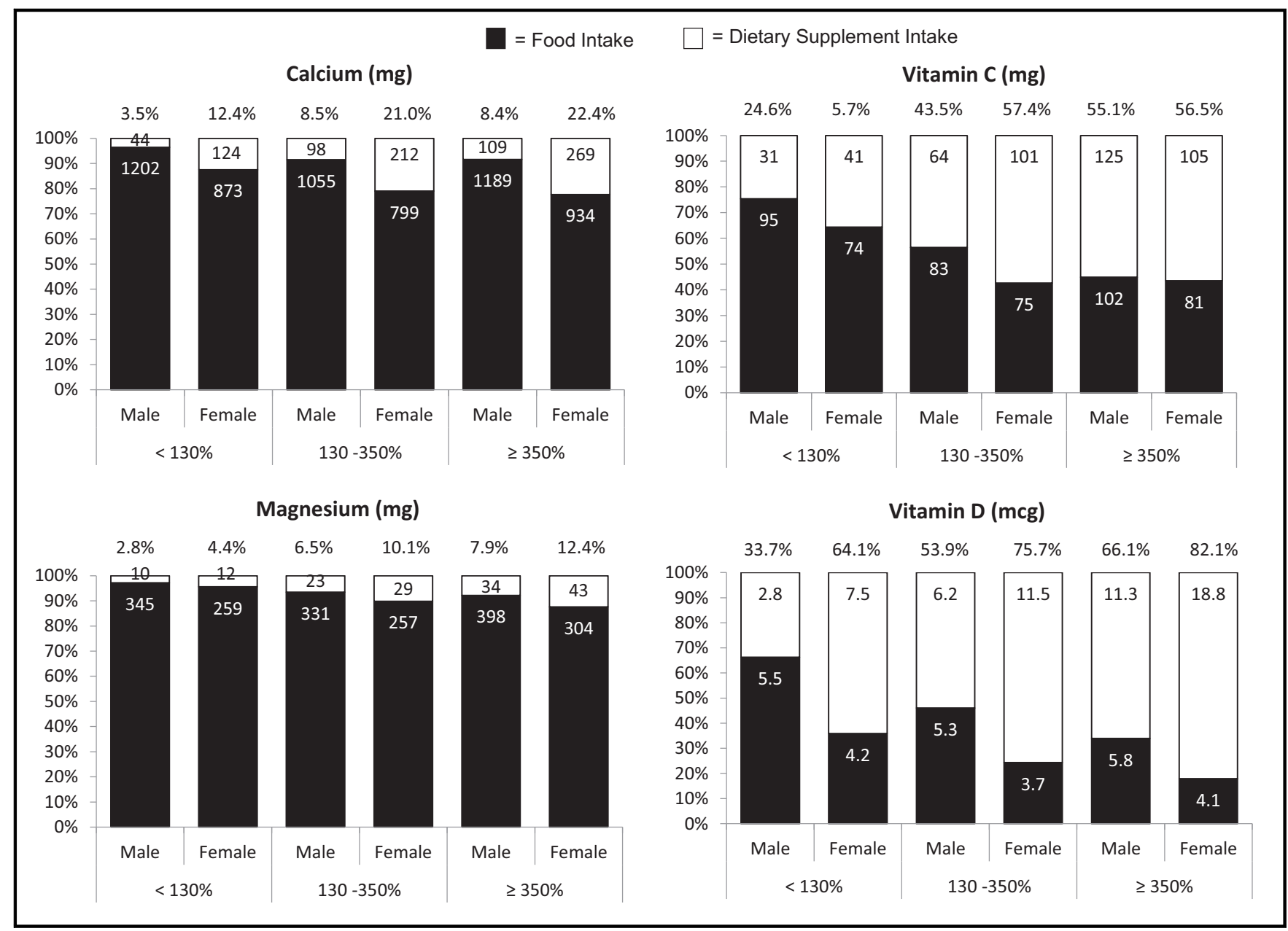

Figure. Relative contribution of foods/beverages and dietary supplements toward total usual mean intake for selected shortfall nutrients by sex and poverty income ratio group among US adults, 2011-2012. Note: The analytic sample includes all individuals aged $\geq 19$ years who were not pregnant, with complete information for poverty-to-income ratio and 24-hour dietary recall data. Percentages above each bar represent the relative contribution from dietary supplements.

those who are considered food insecure.

The cost of food is clearly a driver for consumption patterns and diet quality. ${ }^{39}$ In the US there has been an overall decline in the cost of foods, but the cost of unhealthy foods has dropped more considerably than that for fresh produce and sources of animal protein (ie, dairy and meat). ${ }^{40}$ As described by Darmon and Drewnowski, ${ }^{15}$ the cost of foods has more of an impact on those at the lowest economic position. Engel's law shows that when income increases, the proportion of income spent on food declines. ${ }^{41}$ In the US, approximately $11 \%$ of total income is devoted to food purchases ${ }^{18}$; however, how the cost of food translates to micronutrient intakes is less well understood. In the US context, many foods that are intrinsically low in nutrient density (eg, energy drinks) are voluntarily fortified with micronutrients at the discretion of the manufacturer, which adds substantially to overall micronutrient intakes. ${ }^{42,43}$ Voluntary fortification adds a wrinkle to a traditional nutritionist's dogma because key nutrients are being added to the diet, but the vehicle is often seen as a less nutritionally desirable food choice; this phenomenon may benefit micronutrient intakes of those at the lowest incomes more so than those at higher incomes.

A significant linear trend in the prevalence of US adults who understand federal dietary guidance was documented using the same PIR categories in the current analysis. ${ }^{44}$ The current analysis serves to highlight the impact on micronutrient intakes that may result from the lack of understanding of nutritional guidance and educational efforts geared toward healthy eating. Previous research indicated that compliance with federal nutrition recommendations is especially problematic for those at lower incomes. ${ }^{45}$ The current findings were largely consistent with the Seattle Obesity Study, which suggested that optimal intakes of micronutrients are directly tied to higher-cost foods. ${ }^{46}$ However, because those authors measured diet using a food-frequency questionnaire and did not include dietary supplements, the current researchers cannot extrapolate the findings directly with those in the NHANES. ${ }^{46}$

As with any scientific analysis, one should consider the strengths and limitations of the work in interpreting 
the study findings. First, the researchers use large, nationally representative survey data to illustrate the impact of poverty on nutrition at the national level. Although this contributes to a broad understanding of the issues and interactions, it is likely not descriptive of those at the extremes of the income distribution who may have been unwilling or unable to participate in research studies. Furthermore, PIR may not be the most sensitive indicator of socioeconomic status, which is notoriously difficult to classify. ${ }^{47}$ For this analysis the authors purport that PIR measures how a person's disposable income can be used to access food and dietary supplements. Indeed the authors saw that micronutrient intakes are the best in those with the highest income adjusted for family size and geography. Recent reports used geographic location, property values, and access to retail food shopping stores to estimate this construct. ${ }^{48,49}$

Food insecurity is an evolving area of research and is an important consideration. Studies showed that food insecurity is related to poorer micronutrient intakes from foods alone, with stronger associations seen in Canada than in the US. ${ }^{50}$ Participation in SNAP was associated with lower diet quality and lower intakes of fruit and vegetables, but the micronutrient quality of diets of SNAP participants relative to nonparticipants was not been fully studied. The fact that the current researchers found low intakes among those up to $350 \%$ of PIR (representing more than two third of the sample) suggests that although income is important, there is a group between food-insecure people and those with a relatively high income who continue to have inadequate micronutrient intakes despite the ability to afford better-quality foods. It is possible that those in the higher income group not have only the funds but also have greater education, nutrition knowledge, and health-based motivation to consume foods with higher nutrient density and use nutrient supplements to improve the likelihood of adequacy.

The use of the NCI method to correct for measurement error permitted the researchers to compare population subgroup intakes relative to the Dietary Reference Intake, EAR. Thus, this work extends the data tables of mean micronutrient intakes produced by the US Department of Agriculture, which also documented, with sex combined, an association with PIR. ${ }^{33}$ Despite correction for measurement error, a known limitation of self-reported diet is energy underreporting. ${ }^{51}$ It is less well known how selective energy underreporting influences estimates of micronutrients. ${ }^{52}$ In this analysis, the authors combined 2 methods to measure dietary supplements, leveraging the different measurement error structures of short- and long-term dietary assessment methods. ${ }^{36}$

\section{IMPLICATIONS FOR RESEARCH AND PRACTICE}

The current study serves to highlight the impact of both food and supplement choices on micronutrient intakes of US adults and how these interact with PIR. Fromthesedataitisclearthatsupplement use increases with socioeconomic status, and that such use is associated with higher micronutrient density of the diet. Consistent with this report, dietary supplement users were documented to have higher intakes of micronutrients from food sources alone. ${ }^{23,24}$ Thus, increasing access to affordable sources of micronutrients should be a public health priority to reduce social inequities in nutrition. ${ }^{15,40}$ This report suggests that income improves nutrient intake significantly only among the top third of the population. Greater efforts in availability and affordability of nutrient-dense foods as well as appropriate nutrition education are needed not only for the lowest income groups, but for the majority of Americans. Given that adults in the lowest PIR category are more likely to be overweight or obese, simply adding more food to increase micronutrient intakes is not an ideal public health strategy. ${ }^{53}$ Although they are controversial in terms of their impact on chronic disease prevention, and although most agree that improving dietary quality through foods is the best way toimprovemicronutrient intake, dietary supplements can add key micronutrients to the diet without increasing energy intakes. Therefore, increasing access to dietary supplements among those most at risk for micronutrient deficiency may be warranted for some shortfall nutrients and nutrients of public health concern in US adults.

\section{ACKNOWLEDGMENTS}

This work was supported through an unrestricted educational grant to Columbia University by Pharmavite, LLC. The authors wish to thank Dr Kevin Dodd at the NIH National Cancer Institute for his guidance in using the NCI macros.

\section{REFERENCES}

1. Wells HF, Buzby JC. Dietary Assessment of Major Trends in U.S. Food Consumption, 1970-2005. Washington, DC: Economic Research Service, US Dept. of Agriculture; 2008.

2. Smiciklas-Wright $H$, Mitchell DC, Mickle SJ, Goldman JD, Cook A. Foods commonly eaten in the United States, 1989-1991 and 1994-1996: are portion sizes changing? J Am Diet Assoc. 2003;103:41-47.

3. De SK, Liu X, Monga M. Changing trends in the American diet and the rising prevalence of kidney stones. Urology. 2014;84:1030-1033.

4. Briefel RR, Johnson CL. Secular trends in dietary intake in the United States. Annu Rev Nutr. 2004;24:401-431.

5. US Department of Health and Human Services and US Dept of Agriculture. Dietary Guidelines for Americans 20152020. 8th ed. Washington, DC: US Government Printing Office; 2015.

6. Krebs-Smith SM, Guenther PM, Subar AF, Kirkpatrick SI, Dodd KW. Americans do not meet federal dietary recommendations. J Nutr. 2010;140: 1832-1838.

7. Gahche J, Bailey R, Burt V, et al. Dietary supplement use among U.S. adults has increased since NHANES III (1988-1994). NCHS Data Brief $2011 ;(61): 1-8$.

8. US Department of Agriculture - Economic Research Service. Trends in prevalence rates of food insecurity and very low food security in U.S. households, 19952014. http://www.ers.usda.gov/topics/food -nutrition-assistance/food-security-in-the -us/key-statistics-graphics.aspx\#trends. Accessed December 1, 2015.

9. Ogden CL, Carroll MD, Fryar CD, Flegal KM. Prevalence of obesity among adults and youth: United States, 20112014. NCHS Data Brief 2015;(219):1-8. 
10. Ogden CL, Carroll MD, Kit BK, Flegal KM. Prevalence of obesity and trends in body mass index among US children and adolescents, 1999-2010. JAMA. 2012;307:483-490.

11. Ogden CL, Carroll MD, Kit BK, Flegal KM. Prevalence of childhood and adult obesity in the united states, 2011-2012. JAMA. 2014;311: 806-814.

12. Ogden CL, Lamb MM, Carroll MD, Flegal KM. Obesity and socioeconomic status in children and adolescents: United States, 2005-2008. NCHS Data Brief 2010;(51):1-8.

13. Drewnowski A, Rehm CD. Socioeconomic gradient in consumption of whole fruit and 100\% fruit juice among US children and adults. Nutr J. 2015;14:3.

14. Drewnowski A, Specter SE. Poverty and obesity: the role of energy density and energy costs. Am J Clin Nutr. 2004;79:6-16.

15. Darmon N, Drewnowski A. Contribution of food prices and diet cost to socioeconomic disparities in diet quality and health: a systematic review and analysis. Nutr Rev. 2015;73:643-660.

16. Eicher-Miller H, Park C, Bailey RL. Identifying Nutritional Gaps Among Americans. In: Gallo LL, ed. Dietary Supplements in Health Promotion. New York: CRC Press; 2015.

17. Kant AK, Graubard BI. Secular trends in the association of socio-economic position with self-reported dietary attributes and biomarkers in the US population: National Health and Nutrition Examination Survey (NHANES) 1971-1975 to NHANES 1999-2002. Public Health Nutr. 2007;10:158-167.

18. US Department of Agriculture: Economic Research Service. Food spending as a share of income declines as income rises. Data from the U.S. Bureau of Labor Statistics, Consumer Expenditure Survey; 2014.

19. US Census Bureau. Poverty: 2000 to 2012 American Community Survey briefs. http://www.census.gov/prod/2013pubs/ acsbr12-01.pdf. Accessed April 20, 2016.

20. US Census Bureau. Small area income and poverty estimates: release highlights of 2014. https://www.census.gov/did/www/ saipe/data/highlights/2014.html. Accessed January 5, 2017.

21. Bailey RL, Gahche JJ, Miller PE, Thomas PR, Dwyer JT. Why US adults use dietary supplements. JAMA Intern Med. 2013;173:355-361.

22. Bailey RL, Gahche JJ, Lentino CV, et al. Dietary supplement use in the
United States, 2003-2006. J Nutr. 2011;141:261-266.

23. Bailey RL, Fulgoni VL III, Keast DR, Dwyer JT. Dietary supplement use is associated with higher intakes of minerals from food sources. Am J Clin Nutr. 2011;94:1376-1381.

24. Bailey RL, Fulgoni VL III, Keast DR, Dwyer JT. Examination of vitamin intakes among US adults by dietary supplement use. J Acad Nutr Diet. 2012; 112:657-663.

25. Centers for Disease Control and Prevention. National Health and Nutrition Examination Survey 2011-2012 Overview. https://www.cdc.gov/nchs/nhanes/ nhanes2011-2012/overview_g.htm. Accessed September 1, 2013.

26. Fakhouri TH, Hughes JP, Brody DJ, Kit BK, Ogden CL. Physical activity and screen-time viewing among elementary school-aged children in the United States from 2009 to 2010. JAMA Pediatr. 2013;167:223-229.

27. Bailey RL, Gahche JJ, Thomas PR, Dwyer JT. Why US children use dietary supplements. Pediatr Res. 2013;74:737-741.

28. US Department of Agriculture - Agricultural Research Service. What We Eat in America: Documentation and data sets. http://www.ars.usda.gov/Services/docs. htm?docid=18354. Accessed July 5, 2016.

29. Blanton CA, Moshfegh AJ, Baer DJ, Kretsch MJ. The USDA Automated Multiple-Pass Method accurately estimates group total energy and nutrient intake. J Nutr. 2006;136:2594-2599.

30. Moshfegh AJ, Rhodes DG, Baer DJ, et al. The US Department of Agriculture Automated Multiple-Pass Method reduces bias in the collection of energy intakes. Am J Clin Nutr. 2008;88: 324-332.

31. US Department of Agriculture - Agricultural Research Service. Food and Nutrient Database for Dietary Studies 2011-2012. http://www.ars.usda.gov/Services/docs. htm?docid=12089. Accessed July 6, 2016.

32. Bailey RL, Parker EA, Rhodes DG, et al. Estimating sodium and potassium intakes and their ratio in the American diet: data from the 20112012 NHANES. J Nutr. 2016;146: 745-750.

33. US Department of Agriculture - Agricultural Research Service. What We Eat in America. Www.ars.usda.gov/ nea/bhnrc/fsrg. Accessed April 1, 2016.

34. Dodd KW, Guenther PM, Freedman LS, et al. Statistical methods for estimating usual intake of nutrients and foods: a review of the theory. $J$ Am Diet Assoc. 2006;106:1640-1650.

35. Tooze JA, Midthune D, Dodd KW, et al. A new statistical method for estimating the usual intake of episodically consumed foods with application to their distribution. J Am Diet Assoc. 2006;106:1575-1587.

36. Nicastro HL, Bailey RL, Dodd KW. Using 2 assessment methods may better describe dietary supplement intakes in the United States. J Nutr. 2015;145: 1630-1634.

37. Verkaik-Kloosterman J, Dodd KW, Dekkers AL, van't Veer P, Ocke MC. A three-part, mixed-effects model to estimate the habitual total vitamin D intake distribution from food and dietary supplements in Dutch young children. J Nutr. 2011;141:2055-2063.

38. Garriguet D. Combining nutrient intake from food/beverages and vitamin/mineral supplements. Health Rep. 2010;21:71-84.

39. Rehm CD, Monsivais P, Drewnowski A. Relation between diet cost and Healthy Eating Index 2010 scores among adults in the United States 2007-2010. Prev Med. 2015;73:70-75.

40. Drewnowski A. Nutrition economics: how to eat better for less. J Nutr Sci Vitaminol. 2015;61(suppl):S69-S71.

41. Zimmerman CC. Ernst Engel's Law of Expenditures for Food. Q J Econ. 1932; 47:78-101.

42. Dwyer JT, Wiemer KL, Dary O, et al. Fortification and health: challenges and opportunities. Adv Nutr. 2015;6: 124-131.

43. Fulgoni VL III, Keast DR, Bailey RL, Dwyer J. Foods, fortificants, and supplements: where do Americans get their nutrients? J Nutr. 2011;141: 1847-1854.

44. Wright JD, Wang CY. Awareness of Federal Dietary Guidance in persons aged 16 years and older: results from the National Health and Nutrition Examination Survey 2005-2006. J Am Diet Assoc. 2011;111:295-300.

45. Monsivais P, Aggarwal A, Drewnowski A. Following federal guidelines to increase nutrient consumption may lead to higher food costs for consumers. Health Aff (Millwood). 2011;30:1471-1477.

46. Aggarwal A, Monsivais P, Drewnowski A. Nutrient intakes linked to better health outcomes are associated with higher diet costs in the US. PLoS One. 2012;7:e37533. 
646 Bailey et al

47. Galobardes B, Shaw M, Lawlor DA, Lynch JW, Davey Smith G. Indicators of socioeconomic position (part 1). J Epidemiol Community Health. 2006;60:7-12.

48. Rehm CD, Moudon AV, Hurvitz PM, Drewnowski A. Residential property values are associated with obesity among women in King County, WA, USA. Soc Sci Med. 2012;75:491-495.

49. Horning ML, Fulkerson JA. A systematic review on the affordability of a healthful diet for families in the United

Journal of Nutrition Education and Behavior • Volume 49, Number 8, 2017

States. Public Health Nurs. 2015;32: 68-80.

50. Kirkpatrick SI, Dodd KW, Parsons R, Ng C, Garriguet D, Tarasuk V. Household food insecurity is a stronger marker of adequacy of nutrient intakes among Canadian compared to American youth and adults. J Nutr. 2015; 145:1596-1603.

51. Subar AF, Kipnis V, Troiano RP, et al. Using intake biomarkers to evaluate the extent of dietary misre- porting in a large sample of adults: the OPEN study. Am J Epidemiol. 2003;158:1-13.

52. Subar AF, Freedman LS, Tooze JA, et al. Addressing current criticism regarding the value of self-report dietary data. J Nutr. 2015;145: 2639-2645.

53. Ogden CL, Lamb MM, Carroll MD, Flegal KM. Obesity and socioeconomic status in adults: United States, 20052008. NCHS Data Brief. 2010:1-8.

\section{Welcome to the new Members on JNEB's Board of Editors}

Dalal Alkazemi, PhD

Kuwait University

Jeanette Andrade, PhD

Eastern Illinois University

Natalie Caine-Bish, PhD, RD, LD

Kent State University

John Dawson, PhD

Texas Tech University
Frances Gizis, PhD

Long Island University, Post Campus

Patrick McLaughlin, PhD

USDA - Economic Research Service

Taren Swindle, PhD

University of Arkansas for Medical

Sciences

Jennifer Utter, PhD

University of Auckland 


\section{CONFLICT OF INTEREST}

This work was supported through an unrestricted educational grant to Columbia University by Pharmavite, LLC. 
Supplemental Material 1. Mean (SE) Total Usual Micronutrient Intakes and Prevalence (\% [SE]) Less Than Estimated Average Requirement (EAR), by Poverty Income Ratio (PIR) Group and Sex Among Adult (Aged $\geq 19$ y) Dietary Supplement Users in US, 2011-2012

\begin{tabular}{|c|c|c|c|c|c|c|}
\hline \multirow[b]{2}{*}{ Micronutrient Intake by Sex } & \multicolumn{3}{|c|}{ PIR Group, \% (SE) < EAR } & \multicolumn{3}{|c|}{$P$} \\
\hline & $A(<130 \%)$ & B (130\%-350\%) & C ( $\geq 350 \%)$ & A Vs B & A Vs C & B Vs C \\
\hline Men, $\mathrm{n}$ (mean [SE]) & 261 & 322 & 396 & & & \\
\hline Folate, DFE & $1143(60)$ & $1275(79)$ & $1340(49)$ & .01 & $<.001$ & .29 \\
\hline Calcium, mg & $1385(104)$ & $1368(78)$ & $1489(52)$ & .80 & .80 & .03 \\
\hline Magnesium, mg & $428(18)$ & $425(20)$ & $516(22)$ & .73 & $<.001$ & $<.001$ \\
\hline Vitamin $\mathrm{C}, \mathrm{mg}$ & $273(28)$ & $311(49)$ & $414(54)$ & .34 & .002 & $<.001$ \\
\hline Vitamin D, $\mu \mathrm{g}$ & $20.9(2)$ & $25.7(2)$ & $32.2(5)$ & $<.001$ & .01 & .16 \\
\hline Women, $\mathrm{n}$ (mean [SE]) & 378 & 427 & 424 & & & \\
\hline Folate, DFE & $1214(39)$ & $1130(43)$ & $1200(32)$ & $<.001$ & .53 & .015 \\
\hline Calcium, mg & $1325(46)$ & $1297(50)$ & $1434(79)$ & .15 & .08 & .02 \\
\hline Magnesium, mg & $350(12)$ & $364(17)$ & $426(21)$ & .24 & $<.001$ & $<.001$ \\
\hline Vitamin C, mg & $255(18)$ & $363(48)$ & 297 (42) & .01 & .26 & .004 \\
\hline Vitamin D, $\mu \mathrm{g}$ & $29.0(6)$ & $29.6(2)$ & $36.2(4)$ & .86 & .12 & .08 \\
\hline \multicolumn{7}{|l|}{ Men, $\mathrm{n}(\%<$ EAR [SE]) } \\
\hline Folate, DFE & $7(2)$ & $8(2)$ & 0 & .16 & .01 & .003 \\
\hline Calcium, mg & $12(5)$ & $15(5)$ & $5(1)$ & .22 & .17 & .05 \\
\hline Magnesium, mg & $29(5)$ & $33(5)$ & $12(3)$ & .13 & $<.001$ & $<.001$ \\
\hline Vitamin C, mg & $9(3)$ & $10(1)$ & $3(1)$ & .70 & .05 & $<.001$ \\
\hline Vitamin D, $\mu \mathrm{g}$ & $24(7)$ & $14(3)$ & $13(2)$ & .13 & .12 & .66 \\
\hline \multicolumn{7}{|l|}{ Women, n (\% < EAR [SE]) } \\
\hline Folate, DFE & 0 & $1(0.3)$ & 0 & .004 & 1 & .004 \\
\hline Calcium, mg & $18(3)$ & $23(4)$ & $12(3)$ & .07 & $<.001$ & .003 \\
\hline Magnesium, mg & $19(5)$ & $26(5)$ & $9(2)$ & $<.001$ & .02 & .001 \\
\hline Vitamin C, mg & $4(1)$ & $4(1)$ & $4(1)$ & 1 & 1 & 1 \\
\hline Vitamin $D, \mu \mathrm{g}$ & $19(3)$ & $16(2)$ & $13(3)$ & .14 & $<.001$ & .08 \\
\hline
\end{tabular}

DFE indicates dietary folate equivalents; RAE, retinol activity equivalents; ATE, $\alpha$-tocopherol equivalents.

Note: The analytic sample includes all individuals aged $\geq 19$ years and who were not pregnant with complete information for PIR and 24-hour dietary recall data. Vitamins A and E, and potassium are not included in these estimates. Statistical significance between PIR categories was assessed with multiple $t$ tests using Bonferroni-corrected significant $P \leq .005$. 
Supplemental Material 2. Mean (SE) Total Usual Micronutrient Intakes and Prevalence (\% [SE]) Less Than Estimated Average Requirement (EAR), by Poverty Income Ratio (PIR) Group and Sex Among Adults (Aged $\geq 19$ y) Who Did Not Use Dietary Supplements in US, 2011-2012

\begin{tabular}{|c|c|c|c|c|c|c|}
\hline \multirow[b]{2}{*}{ Micronutrient Intake by Sex } & \multicolumn{3}{|c|}{ PIR Group, \% (SE) < EAR } & \multicolumn{3}{|c|}{$\boldsymbol{P}$} \\
\hline & $A(<130 \%)$ & B (130\%-350\%) & $C(\geq 350 \%)$ & A Vs B & A Vs C & B Vs C \\
\hline \multicolumn{7}{|l|}{ Men, n (mean [SE]) } \\
\hline Folate, DFE & $624(31)$ & $635(26)$ & $681(26)$ & .51 & $<.001$ & $<.001$ \\
\hline Calcium, mg & $1210(71)$ & $1036(40)$ & $1135(37)$ & .003 & .21 & $<.001$ \\
\hline Magnesium, mg & $343(9)$ & 327 (10) & $385(16)$ & $<.001$ & .001 & $<.001$ \\
\hline Vitamin C, mg & $91(9)$ & $82(5)$ & $89(6)$ & .22 & .76 & .03 \\
\hline Vitamin $\mathrm{D}, \mu \mathrm{g}$ & $5.6(0.5)$ & $5.2(0.3)$ & $5.5(0.2)$ & .33 & .83 & .19 \\
\hline Women, n (mean [SE]) & 476 & 330 & 216 & & & \\
\hline Folate, DFE & $484(21)$ & $424(12)$ & $536(18)$ & $<.001$ & $<.001$ & $<.001$ \\
\hline Calcium, mg & $838(23)$ & $772(32)$ & $895(36)$ & .003 & .03 & $<.001$ \\
\hline Magnesium, mg & $250(6)$ & $251(7)$ & $291(8)$ & .78 & $<.001$ & $<.001$ \\
\hline Vitamin $\mathrm{C}, \mathrm{mg}$ & $68(7)$ & $65(4)$ & $84(7)$ & .60 & $<.001$ & $<.001$ \\
\hline Vitamin D, $\mu \mathrm{g}$ & $4.0(0.2)$ & $3.5(0.1)$ & $4.0(0.3)$ & .01 & 1 & .09 \\
\hline \multicolumn{7}{|l|}{ Men, $\mathrm{n}(\%<$ EAR [SE]) } \\
\hline Folate, DFE & $6(1)$ & $8(3)$ & $2(1)$ & .45 & .65 & .48 \\
\hline Calcium, mg & $18(3)$ & $34(4)$ & $20(3)$ & $<.001$ & .16 & $<.001$ \\
\hline Magnesium, mg & $54(4)$ & $61(4)$ & $41(5)$ & $<.001$ & $<.001$ & $<.001$ \\
\hline Vitamin $\mathrm{C}, \mathrm{mg}$ & $50(6)$ & $57(3)$ & $49(4)$ & .23 & .84 & .008 \\
\hline Vitamin D, $\mu \mathrm{g}$ & $91(3)$ & $94(2)$ & $91(2)$ & .24 & 1 & .01 \\
\hline \multicolumn{7}{|l|}{ Women, $\mathrm{n}(\%$ < EAR [SE]) } \\
\hline Folate, DFE & $15(7)$ & $31(3)$ & $6(2)$ & .02 & .19 & $<.001$ \\
\hline Calcium, mg & $57(3)$ & $68(5)$ & $50(5)$ & .01 & .09 & $<.001$ \\
\hline Magnesium, mg & $60(4)$ & $60(3)$ & $40(4)$ & .99 & $<.001$ & $<.001$ \\
\hline Vitamin C, mg & $54(6)$ & $56(3)$ & $32(5)$ & .70 & $<.001$ & $<.001$ \\
\hline Vitamin $\mathrm{D}, \mu \mathrm{g}$ & $99(0.7)$ & $99(0.3)$ & $99(1)$ & 1 & 1 & 1 \\
\hline
\end{tabular}

DFE indicates dietary folate equivalents; RAE, retinol activity equivalents; ATE, $\alpha$-tocopherol equivalents.

Note: The analytic sample includes all individuals aged $\geq 19$ y who were not pregnant, and who had complete information for PIR and 24-hour dietary recall data. Vitamins $A$ and $E$ and potassium are not included in these estimates. Statistical significance between PIR categories was assessed with multiple $t$ tests with Bonferroni-corrected significant $P \leq .005$. 